\title{
Evidence on industry influence should be in the core medical curriculum
}

\author{
Ben Goldacre research fellow \\ London School of Hygiene and Tropical Medicine, London WC1E 7HT, UK
}

Smith and colleagues all agree that the drug industry can mislead doctors and distort medical practice, but they disagree on how to police the problem. ${ }^{1}$

One important option has been oddly neglected. The extensive research evidence documenting industry's influence on medical practice should be a core feature of all curriculums for medical school and membership exams.

Our current model is to give trainees some pointers on basic study design and critiquing an individual academic manuscript. This is plainly not enough, given what we now know about the extent of withheld trial information, misleading trial reports, manipulation of the academic literature, and the biased dissemination of evidence through marketing. ${ }^{2}$

The importance of these problems should not be overlooked. After initial close supervision and training, doctors go off to practise medicine independently for several decades. During this time they are responsible for updating their knowledge, while medicine changes all around them. Depending on specialty, doctors who qualified in the 1970s could easily find themselves almost exclusively using drugs that came on the market long after they left formal training. Such doctors will be essentially self taught about these drugs and barraged with information of variable quality, from an industry with global revenues of $\$ 900 \mathrm{bn}$ ( $£ 552 \mathrm{bn}$; $€ 666 \mathrm{bn}$ ), which is incentivised to keep sales of individual drugs high.

Doctors in this situation should clearly be taught about the pitfalls in claims made by industry and the evidence on biased dissemination. This is not a radical suggestion, and it does not imply that the drug industry — which has created many lifesaving products - is a universally malevolent influence. It is simply a pragmatic approach to improving evidence based practice, in the face of influences that seek to distort prescribing decisions.

Competing interests: I am a doctor and a patient. I receive income from speaking and writing for lay audiences on problems in science and medicine, including the influence of industry on prescribing.

1 Smith R, Gøtzsche PC, Groves T. Should journals stop publishing research funded by the drug industry? BMJ 2014;348:g171. (14 January.)

2 Spurling GK, Mansfield PR, Montgomery BD, Lexchin J, Doust J, Othman N, et al. Information from pharmaceutical companies and the quality, quantity, and cost of physicians' prescribing: a systematic review. PLoS Med 2010;7:e1000352.

Cite this as: BMJ 2014;348:g1390

๑ BMJ Publishing Group Ltd 2014 